\title{
Algunas reflexiones en torno al análisis de la música popular rioplatense de entresiglos a propósito del estilo de "Juan Moreira"
}

\author{
Some reflections on the analysis of rioplatense popular music \\ at the turn of the century, with regard to the estilo of \\ "Juan Moreira"
}

\author{
por \\ Daniela González \\ Universidad de Buenos Aires, Argentina \\ danabel.gonzalez@gmail.com
}

En este artículo se examinan las limitaciones que presentan los abordajes analíticos centrados en la caracterización formal a la hora de estudiar las expresiones musicales populares desarrolladas en la urbe bonaerense entre finales del siglo XIX y comienzos del XX. Con el objetivo de dar cuenta de estas limitaciones, es analizado un estilo para voz y guitarra interpretado a finales del siglo XIX en las adaptaciones escénicas de la novela Juan Moreira de Eduardo Gutiérrez. En primer término, son introducidas las definiciones de este género halladas en una serie de trabajos musicológicos tempranos y es examinada la influencia que las mismas tienen en su análisis. En segundo término, es caracterizado y contextualizado el estilo de la obra Juan Moreira, y realizado un análisis de sus rasgos formales entre finales del siglo XIX y las primeras décadas del siglo XX. Finalmente son estudiados los aspectos performativos y los procesos de significación del ejemplo seleccionado y, a partir de ello, son puestas en evidencia las tensiones que surgen entre las conceptualizaciones etic y emic de este género.

Palabras clave: música popular bonaerense, análisis musical, estilo, Eduardo Gutiérrez.

This article evaluates the limitations that formalist musical analysis finds when studying the popular music developed in Buenos Aires between the late nineteenth and early twentieth century. In order to account for these limitations, we analyze an estilo (a vocal popular music genre usually accompanied by guitar) played at the end of the nineteenth century in the theatre and circus adaptations of the novel Juan Moreira written by Eduardo Gutierrez. Firstly, we introduce the definitions of this genre found in some early musicological works and we examine the influence that these definitions have in the estilo's analysis. Secondly, the estilo played in Juan Moreira is described and contextualized, and it is developed a formal musical analysis of its changes between the end of the nineteenth century and the first decades of the twentieth century. Finally, we study the particular performance and the signification processes of the selected example and, after that, we highlight the tensions that arise between the etic and emic conceptualizations of this genre.

Keywords: Bonaerense Popular music, musical analysis, estilo, Eduardo Gutiérrez. 


\section{INTRODUCCIÓN ${ }^{1}$}

Ancladas en la tradición oral y vigentes en un imaginario colectivo cambiante, las expresiones musicales populares que confluyen en la urbe bonaerense entre finales del siglo XIX y comienzos del XX requieren para su (re)construcción -como muchas otras expresiones populares de la época- el escrutinio crítico, atento e, incluso, creativo de una multiplicidad de documentos que ofrecen datos fragmentarios y dispares. Teniendo en cuenta su momento de producción y el modo en que es tratada la información que contienen, dichos documentos pueden ser clasificados, fundamentalmente, en dos grupos. El primero reúne la documentación producida durante el entresiglo ${ }^{2}$ por sus protagonistas o testigos directos que contiene descripciones más o menos detalladas, ejemplos -parciales o totales- o valoraciones de toda práctica musical popular. Entre estos documentos se hallan: 1) publicaciones periódicas dedicadas al arte $\left.{ }^{3} ; 2\right)$ folletos y pliegos sueltos con poesías para cantar 4 ; 3) cancioneros populares recopilados por investigadores argentinos ${ }^{5}$ o extranjeros; 4) memorias de personajes de la escena artística local ${ }^{6}$; y 5) la colección de 126 cilindros de cera grabados por Robert Lehmann-Nitsche en 1905 en la ciudad de La Plata ${ }^{7}$. El otro conjunto documental se encuentra constituido por escritos producidos generalmente $a$ posteriori, en los que se realiza una interpretación, análisis o evaluación de dichas expresiones musicales. Se trata de artículos musicológicos tempranos, con aspiración científica, dedicados mayormente al estudio formal de estas músicas y a su clasificación en géneros o especies. Sirvan como ejemplo los trabajos de Ventura Lynch (1953 [1883]), Vicente Rossi (1926), Josué T. Wilkes e Ismael Guerrero Cárpena (1946), Carlos Vega (2010a [1944] y 2010b [1981]) e Isabel Aretz (1952). Si bien estos estudios se encuentran condicionados por decisiones epistemológicas, metodológicas, ideológicas y políticas pocas veces explícitas, sus interpretaciones han sido en muchos casos adoptadas y reproducidas como verdades. La influencia de estos trabajos en los estudiosos locales ha contribuido, en parte, a constituir lo

1 Agradezco a Enrique Cámara de Landa y a Silvina Argüello por sus valiosos aportes a la tarea de transcripción y análisis del estilo.

2 El término entresiglo o entresiglos ha sido empleado de manera generalizada por estudiosos de diferentes áreas, como la literatura, el teatro y la historia, para hacer referencia al período que se extiende entre finales del siglo XIX y comienzos del XX (ver, por ejemplo: Marengo 2004, Newland 1999, Salto 2006, Shirkin de Testado 2007, Zanetti 1997). En ese mismo sentido se emplea en este artículo.

3 Por ejemplo: El mundo del arte (1891-1895), La gaceta musical (1880-1887), La crónica teatral (1877), La tradición (1904), La enramada (1904), La aurora (1905), Revista criolla (1903).

4 Un volumen significativo de ellos se localizan en la llamada Colección Biblioteca Criolla recopilada por el investigador alemán Robert Lehmann-Nitsche durante su estancia en Argentina entre 1880 y 1925. Si bien en los folletos de esta colección es completamente infrecuente encontrar transcripciones musicales, los mismos ofrecen abundante información de la circulación de la música popular en el escenario rioplatense. En este conjunto documental se encuentran: a) Poesías con rótulos como "milonga", “canción”, "vidalita", “estilo", “pericón”, etc.; b) Poesías acompañadas por aclaraciones como "para cantar con guitarra" o "para tocar en los bailes nacionales"; c) textos prescriptivos en los que se define, por ejemplo, cómo debe afinarse la guitarra para interpretar un determinado conjunto de poesías.

5 Los de Andrés Chazarreta, Juan Alfonso Carrizo, Juan Draghi Lucero o Alberto Rodríguez, entre otros.

6 Como, por ejemplo, las memorias de José Podestá (2003 [1930]).

7 Los mismos se encuentran alojados en el Archivo Fonográfico de Berlín, colección 193, "Música criolla" (Ziegler 2006: 471). Asimismo, existe una copia completa de estos registros en el archivo del Instituto Nacional de Musicología Carlos Vega. 
que Miguel García denomina una "narrativa canónica” de la música popular (García 2006: 38), la que ha orientado las preocupaciones, intereses y discusiones dentro del campo ${ }^{8}$.

Con el objetivo de reflexionar acerca de la perspectiva metodológica que subyace a dicha "narrativa canónica", en este artículo me propongo dar cuenta de la compleja trama de factores que componen las expresiones musicales populares desarrolladas en la urbe bonaerense durante el entresiglo; ensayar un estudio diacrónico y amplio que, a partir de la indagación y contrastación de fuentes heterogéneas, permita poner de manifiesto el carácter fundamentalmente dinámico de estas expresiones; y repensar las limitaciones de los análisis formalistas. Para ello centro este estudio en un estilo para voz y guitarra interpretado a finales del siglo XIX en las adaptaciones escénicas de la novela Juan Moreira (Gutiérrez 1980 [1879-1880]). En primer lugar, presento las definiciones que ha recibido este género en los escritos musicológicos tempranos y examino las implicancias que dichas definiciones tienen en su análisis. En segundo lugar, caracterizo el "estilo de Moreira", lo contextualizo y analizo sus rasgos formales entre finales del siglo XIX y las primeras décadas del XX. Por último, indago en sus aspectos performativos y procesos de significación, y en las tensiones entre las conceptualizaciones etic y emic de este género.

\section{EL ESTILO: ENTRE LA DELIMITACIÓN TEÓRICA Y LA LIBERTAD PRÁCTICA}

Desde finales del siglo XIX es posible encontrar referencias al estilo en la literatura acerca del folclor. En 1883, en su obra La Provincia de Buenos Aires hasta la definición de la cuestión Capital de la República ${ }^{9}$, Ventura R. Lynch describe el estilo ${ }^{10}$ como un género no bailable, musicalmente muy variado, compuesto en versos octosilábicos de elevada "inspiración poética" e interpretado con acompañamiento de guitarra ${ }^{11}$. Vicente Rossi, por su parte, le adjudica origen uruguayo y lo define como un tipo muy difundido de canción rioplatense que se interpreta con acompañamiento de guitarra, se articula en décimas ${ }^{12}$ y posee una música de carácter libre y "de singular belleza" (Rossi 1926: 353).

En su libro Formas musicales rioplatenses. Su origen hispánico, Josué T. Wilkes e Ismael Guerrero Cárpena ${ }^{13}$ afirman que el estilo surge de la búsqueda de una expresión musical de carácter sentimental que -a diferencia de la media milonga en modo menor- permita la exteriorización del sentir del gaucho sin ceñirlo a una forma rígida. A su entender, el estilo surge y se desarrolla en el área de Buenos Aires en donde alcanza su máxima expresividad y "belleza” (Wilkes y Guerrero Cárpena 1946: 121-122). Más tarde se extiende hacia otras provincias en las que sufre "distorsiones" y "empobrecimientos". Respecto de sus rasgos formales, los autores afirman que está constituido por: 1) una primera frase,

8 Algunas observaciones respecto de este tema en González 2017a.

9 Reeditada, luego, bajo el título Folklore bonaerense (1953).

10 El autor emplea los términos "estilo" y "décima" como sinónimos.

11 La misma puede estar "templada", según el autor, de diferentes maneras: 1) la sexta y la primera cuerda en mi, la segunda en si, la tercera en sol, la cuarta en re y la quinta en la; 2) la cuarta y la primera cuerda en re, la segunda en sol, la tercera, la quinta y la sexta en sol -o la sexta en fa natural (Ventura Lynch 1953 [1883]: 33-41).

12 Se trata de una combinación métrica de diez versos octosílabos muy difundida en el ámbito poético popular hispanohablante (en particular americano). Su expresión más frecuente, la décima espinela, posee la siguiente rima: abba ac cddc.

13 Los autores analizan el estilo periodizando su desarrollo en tres etapas. A su entender, en cada nueva etapa se cristalizan los rasgos más evolucionados del género, presentes de manera embrionaria en la anterior (Wilkes y Guerrero Cárpena 1946: 131-187). En la definición que articulo aquí retomo, justamente, los rasgos que llegan a cristalizarse luego de su evolución. 
tética, generalmente de ritmo binario (nombrada como A y subdivisible en dos incisos); 2) una segunda frase (B) anacrúsica y rítmicamente contrastante que otorga variedad a la especie; y 3) la reexposición de la primera frase. Aunque se compone en modo menor es frecuente hallar estilos con modulaciones a su relativa mayor.

Carlos Vega define el estilo como una especie lírica descendiente del triste peruano y fuertemente arraigada en Argentina a partir de 1830 (Vega en Goyena y Cirio 2015: 18). Gracias a su extenso trabajo de campo consigue constatar su pertenencia a lo que llama el cancionero ternario colonial y el criollo occidental ${ }^{14}$. Por su parte, Isabel Aretz -quien también categoriza el estilo como una especie lírica- afirma que el mismo se encuentra "compuest[o] por dos temas: el cantable o tema propiamente dicho, en movimiento moderado, y otro [de] tiempo movido, llamado popularmente 'alegro' o 'alegre', aunque metronómicamente no corresponda sino a un poco più con respecto al tema inicial” (Aretz 1952: 144, destacado en el original). En relación con el ritmo, afirma que se trata de una expresión muy libre posible de ser pautada con ritmos básicos que "en la práctica el cantor modifica a su albedrío" (Aretz 1952: 145). Esto da lugar a la alternancia de pies binarios y ternarios que provocan birritmias horizontales, a las que se suman las verticales dadas por las diferencias entre melodía y acompañamiento. Respecto del texto, Aretz afirma que los estilos se cantan con poesías tradicionales aunque reconoce la existencia de "ciertos estilos del sur, que responden a una corriente 'gauchesca' más o menos moderna, debida generalmente a poetas conocidos" (Aretz 1952: 145). En lo relativo al modo de ejecución, la autora advierte que el acompañamiento de guitarra resulta una constante y que la melodía puede ser interpretada a una voz, a dúo en terceras paralelas o bajo la forma de "canto cruzado 15 " -dependiendo, en muchos casos, de la zona geográfica-.

En el folleto redactado por Bruno Jacovella que acompaña la antología musical Canciones folklóricas de la argentina (Jacovella 1983), el estilo es descrito como un género con una estructura estilísticamente dual que se compone por un tema de triste seguido por otro con aire de zamba. Respecto de las características de cada uno de estos temas, el autor afirma que:

El primero, llamado el Grave, suele ser lento, de expresión noble y tendencia descendente; sus pies binarios se subrayan a menudo con punteo de guitarra en las bordonas; el segundo, llamado Alegre o Alegro (Kimba por Vega), tiene un carácter más arioso, un ritmo más cadencioso, sin ser su movimiento mucho más vivo, y preponderan en él los pies ternarios o dactílicos (1 corchea con 2 semicorcheas) (Jacovella 1983: 8, destacado en el original).

En todos estos trabajos se presenta una definición del estilo en la que se alude, con mayor o menor precisión, a: 1) su pertenencia a la categoría de música cantada; 2) sus rasgos formales -la existencia de dos temas relativamente contrastantes, el empleo del modo menor, el uso de poemas en décimas, la alternancia rítmica-; 3) algunas características de la interpretación -el acompañamiento de guitarra, el canto a dúo en terceras paralelas-;

14 Es interesante observar que también alude al estilo cuando se refiere al "cancionero platense", denominación que acuña para dar cuenta de un conjunto de "vestigios tonales" que sobreviven "curiosamente" en el Río de la Plata y de los que no consigue dar una explicación convincente (Vega 2010a [1944]: 217-221).

15 Este modo de interpretación vocal consiste en la alternancia de los diferentes versos de una estrofa entre uno y otro cantor, y el reencuentro a dúo -generalmente por terceras- en algunos estribillos o al final de algunas estrofas (Aretz 1952: 142). 
4) el lugar geográfico donde se origina y aquel/los hacia dónde se difunde -sobre lo que no hay acuerdo-; y 5) aspectos estéticos presuntamente objetivos expresados desde una perspectiva etic. Es decir, el estilo en tanto especie o género es entendido como un conjunto de propiedades musicales y poéticas relativamente estables ${ }^{16}$, con características estéticas inmanentes, y con un origen geohistórico y una trayectoria de difusión particulares. Incluso cuando algunos autores señalan el carácter libre del ritmo, tienden a explicarlo como una variación que ocurre en la situación performativa -condicionada por la voluntad del intérprete-. Asimismo, el ritmo es el único parámetro que se considera cambiante. Las transformaciones en cualquiera de los otros son interpretadas como desviaciones respecto de la norma, desviaciones que -en la mayoría de los casos- restan belleza al género.

A este conjunto de definiciones subyace una noción de música "como 'artefacto' o 'texto', habitualmente fijado en la partitura”17. Como afirma María Nagore, las perspectivas analíticas que derivan de este tipo de definiciones se centran, fundamentalmente, en la "determinación y explicación de los elementos formales y estructurales" y en la elucidación de la "coherencia interna" de la obra ${ }^{18}$. Estas estrategias analíticas, que tienden a desligar las expresiones musicales de las prácticas sociales, de los sujetos que las producen, reproducen y significan, y de su devenir temporal, han sido cuestionadas y repensadas desde diferentes perspectivas ${ }^{19}$. En consonancia con algunos de estos cuestionamientos, y con el fin de reflexionar acerca del enfoque analítico cristalizado en la bibliografía mencionada -y extendido en los estudios musicológicos argentinos- en este trabajo me propongo reconstruir la trama de factores heterogéneos que componen el estilo para voz y guitarra empleado como música diegética en las adaptaciones escénicas ${ }^{20}$ de la novela folletinesca Juan Moreira de Eduardo Gutiérrez. Para ello: 1) recopilo los enunciados que lo definen -asociándolo a un texto poético específico y a un rol en la obra escénica-y que dan cuenta de su pervivencia a lo largo del tiempo; 2) realizo el análisis musical de tres versiones ${ }^{21}$ de este estilo; y 3) examino cuestiones relativas a la performance y a la significación. Mediante el estudio de este caso busco articular un abordaje diacrónico y amplio que se distancie de los análisis formalistas centrados, fundamentalmente, en el fenómeno musical "escindido artificialmente de sus contextos" (Grebe Vicuña 1991: 14), sin por eso dejar enteramente de lado sus rasgos formales.

16 Una síntesis de las discusiones en torno a la noción de género en los estudios de música popular en Guerrero 2012.

17 Nagore 2004: s/n. http://www.eumus.edu.uy/revista/nro1/nagore.html [último acceso: 26 de junio de 2017].

18 Nagore 2004: s/n. http://www.eumus.edu.uy/revista/nrol/nagore.html [último acceso: 26 de junio de 2017].

19 Ver, por ejemplo: Frith 2014 [1998]; González 2013; Grebe Vicuña 1991; Middleton 1960; Nagore 2004; Tagg 1979, 1982; Tagg y Clarida 2003.

20 Esta novela fue adaptada en primer lugar al circo como pantomima y luego al teatro como drama criollo.

21 La noción de "versión" es empleada en este artículo para aludir, en términos generales, a cada nueva interpretación o puesta en música del mismo texto poético. De manera más específica, y retomando las reflexiones de Rubén López Cano (2013), la versión es entendida como la actualización de una performance preexistente (en este caso, la interpretación del estilo que realiza José Podestá en la adaptación escénica de Juan Moreira) que pervive en el imaginario colectivo de la época como "referente" (o posible "original cronológico", López Cano 2013: 87). Aun cuando es imposible reconstruir sus rasgos musicales o saber si, efectivamente, se trata de la "primera interpretación" de esta pieza, la misma es socialmente identificada como "punto de origen" o "referencia" (López Cano 2013: 83). Por lo antedicho, aquella interpretada por Podestá no es nombrada aquí como "original", pero sí son identificados todos los ejemplos posteriores como "versiones" (que la actualizan de maneras formalmente diversas). 


\section{SU MENCIÓN MÁS TEMPRANA: EL ESTILO QUE DA VOZ A MOREIRA}

Tanto Vicente Rossi (1926: 354-355) como José Podestá (2003 [1930]: 51) y Carlos Vega (2010b [1981]: 38) describen el estilo objeto de este estudio como parte de la pantomima circense Juan Moreira. Los tres autores afirman que el protagonista de la obra-interpretado por el propio Podestá- lo cantaba, acompañado por su guitarra, con la siguiente décima del poema Lázaro de Ricardo Gutiérrez:

El hondo pesar que siento

y ya el alma me desgarra,

sollozo en esta guitarra

y está llorando en mi acento:

como es mi propio tormento

fuente de mi inspiración,

cada pie de esta canción

lleva del alma un pedazo,

y en cada nota que enlazo

se me parte el corazón.

(Gutiérrez 1901 [1869]: 175. "Canto Primero").

Ninguno de ellos menciona si sucedían a esta décima otras -del mismo o de diferentes poemas-, o si en el marco de la representación escénica solo era cantada dicha estrofa.

La inclusión de este estilo en una obra que representa la acción por medio de gestos y movimientos, prescindiendo por completo de la palabra, parece haber sido un hecho significativo en la época. En sus memorias Podestá asevera que en el estreno de la pantomima, en julio de 1884, la audiencia escuchó "por primera vez [...] cantar un estilo en una obra" lo que hizo que "el entusiasmo se apoder[ara] de ella" (Podestá 2003 [1930]: 51). A su vez, añade que "solo el gato con relaciones y el estilo que cantaba Moreira [...] interrumpían el mutismo de los actores" (Podestá 2003 [1930]: 51). Por su parte, Beatriz Seibel observa que en dicha pantomima "solo se usa[ba] la voz para entonar el Estilo" (Seibel 1993: 57) y Vega destaca que, si bien a lo largo de la obra la banda del circo intervenía en numerosas oportunidades con el fin de reforzar el efecto de algunas situaciones o de ambientar ciertas escenas, dicha música no participaba en la acción representada como sí lo hacía el estilo (Vega 2010b [1981]: 38, 34-44). Finalmente, en el libro Memorias de un hombre de teatro, Enrique García Velloso reproduce un diálogo que, según enuncia, tuvo en 1921 con el protagonista de la pantomima circense en la recepción ofrecida por el Círculo Argentino de Autores en honor a Camila Quiroga. En este intercambio, Podestá devela algunos detalles del surgimiento de Juan Moreira y destaca, además, que en la obra

[t] oda la acción era conducida a favor de la mímica, que poco a poco resultó perfeccionada, hasta al punto de subsistir en lo posible a las palabras, que solamente se oyeron cuando canté aquellas décimas de Ricardo Gutiérrez, que empiezan diciendo: "El hondo pesar que siento - y ya el alma me desgarra..."; y cuando mis otros compañeros recitaron las relaciones del "Gato"22.

22 García Velloso 1942: 157. Fragmentos de este libro son publicados en el número 290 (año XV $2^{\circ}$ época, 1952) de Argentores. Revista Teatral bajo el título "Para la historia anecdótica del teatro argentino", con motivo de la preparación de un "homenaje a la memoria de José J. Podestá" (41). 
Aun cuando en ninguna de estas fuentes se ahonda en las consecuencias de la relación "obra escénica muda/ obra musical vocal", en todas se destaca de manera más o menos explícita la importancia expresiva de esta inclusión.

\section{UNA VOZ QUE (RE)SUENA: EL ESTILO DE MOREIRA EN LA COLECCIÓN "MÚSICA CRIOLLA"}

En 1905, más de veinte años después de aquella supuesta primera aparición, una versión de este estilo fue grabada por Robert Lehmann-Nitsche en la ciudad de La Plata. La misma, registrada en dos cilindros, es interpretada por el payador Anastasio Rodríguez y forma parte de la colección "Música Criolla23". Esta colección es una de las ocho realizadas por el investigador alemán durante su estadía en Argentina y está compuesta por 126 cilindros de cera grabados en la ciudad de La Plata y en Ensenada entre el 16 de febrero y el 19 de mayo de 1905 (García 2009: 81-82).

En esta versión del estilo, además de la citada décima de Lázaro se escuchan las siguientes dos, del mismo poema ${ }^{24}$ :

Te vi y aunque no sentiste

en mi soledad te amé

con esa (la) profunda fe

que óto (hay) en un alma triste:

tú en un palacio naciste,

yo en un desierto nací

y aunque en el alma sentí

fuerzas para alzarme al cielo,

la suerte cortó mi vuelo

y hasta el infierno caí.

Como fiera perseguida

piso una senda de abrojos

sin sueño para mis ojos

ni venda para mi herida,

sin descanso ni guarida

ni esperanza ni piedad,

y en fúnebre soledad

a mi dolor amarrado

voy a la muerte arrastrado

por mi propia tempestad.

(Gutiérrez 1901 [1869]: 175-176. "Canto Primero").

A continuación de las mismas es cantada una más, de carácter anónimo:

El gran Salomón lloró

la ausencia de su querida.

23 Cilindros quince y dieciséis de la colección, grabados el 18 de marzo de 1905 según el manuscrito de Lehman-Nitsche Folklore Argentino 1905.

24 Han sido tachados los términos del poema de Gutiérrez que son modificados en la grabación y colocados entre paréntesis aquellos empleados en su lugar. 
Marco Antonio dio la vida a los pies de la que amó. Que es extraño llore yo esta cruel separación que acaso a mi corazón no es digno de lamentarse por qué el privarle quejarse cuando le sobra razón.

En el libro de Juan Alfonso Carrizo Antecedentes hispano-medioevales de la poesía tradicional argentina (1945), se transcribe un canto cuya primera décima se asemeja a la anteriormente citada. Este canto forma parte del Cancionero popular del Tucumán (Carrizo 1937) recopilado por el mismo autor y es, a su entender, un ejemplo de cómo el "afán de erudición", propio de los poetas medievales españoles ${ }^{25}$, permeó los cantos tradicionales argentinos. La primera décima es la siguiente:

Lloró el sabio Salomón

Por una princesa infiel.

Lloró Jacob por Raquel

Y por Dalila, Sansón;

Lloró también Absalón

De Rufina la impiedad;

Lloró Apolo, tal deidad;

Y tú, sin llorar queréis,

Para que al fin descanséis,

Llorá, corazón, llorá.

(Carrizo 1945: 84-85).

Tanto en el Cancionero popular cuyano (1938) recopilado por Alberto Rodríguez como en el homónimo reunido por Juan Draghi Lucero (1938: 75) se encuentran sendas tonadas ${ }^{26}$ tituladas "El gran Salomón". Los versos de las mismas coinciden, aunque con ligeras variaciones ${ }^{27}$, con los de la décima final de la versión grabada por Lehmann-Nitsche.

\section{UN ANÁLISIS MUSICAL DIACRÓNICO: TRES VERSIONES, UN ESTILO}

La grabación del estilo realizada en la ciudad de La Plata es la fuente que más información provee respecto de lo estrictamente musical -y de cuestiones relativas a la performance, como se verá más adelante-. A causa de que el nivel de la señal sonora de la guitarra es bajo resulta difícil precisar en qué consiste el acompañamiento. La línea de la voz, en cambio, se escucha con claridad. A continuación transcribo la melodía completa con los versos de la primera décima -ya que los restantes son interpretados con la misma música- (ver Figura 1).

25 Con "afán de erudición" o "afán erudito" el autor alude a la proliferación en los cantares medievales de referencias a: 1) personajes bíblicos y de la mitología e historia grecolatina; 2) ciudades y naciones de la antigüedad clásica (Carrizo 1945: 83).

26 Según Isabel Aretz (1952), "tonada" es el modo en que denominan el estilo o una especie con iguales características en varias provincias de la región cuyana, en Neuquén y en Chile.

27 En la transcripción de Draghi Lucero, por ejemplo, el quinto verso es "Qué extraño es que llore yo", los versos séptimo y octavo "Loa mi corazón no le es dable lamentarse" y el anteúltimo "De qué le sirve quejarse". 


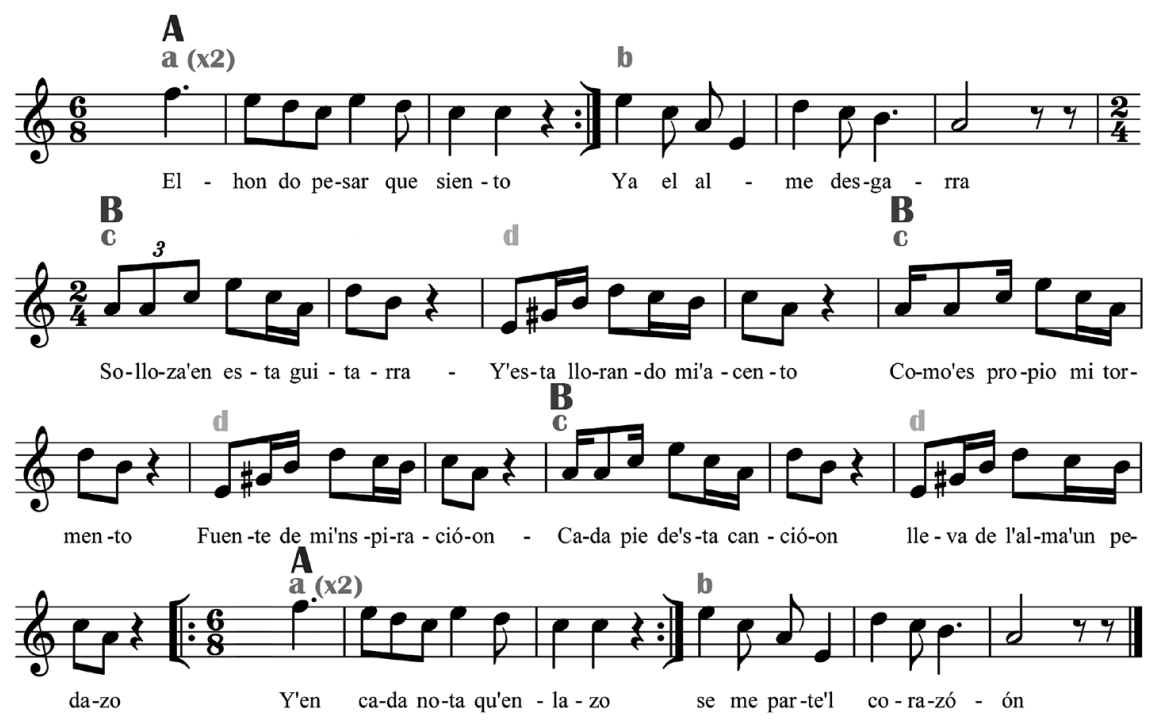

Figura 1: El hondo pesar, primera versión.

Como se puede observar, este estilo se encuentra en la tonalidad de la menor armónica y está compuesto por dos frases musicales -o temas, en términos de Aretz (1952: 144) y Jacovella (1983: 8)-, que se alternan dando lugar a la siguiente forma: A B B B A. Asimismo, las frases están conformadas por un antecedente y un consecuente, que se suceden de esta manera: a (a)b cd cd cd a (a)b. Cada uno de ellos coincide con un verso octosilábico de la décima. Aun cuando por cuestiones formales la frase A ha sido pautada de manera rigurosa, la misma es rítmicamente libre y cambiante, y su tempo es lento. En ella, el intérprete emplea el rubato de forma frecuente llegando a desdibujar el pulso por completo. El antecedente de A -que abarca los compases 1 y 2 y su reexposición en 18-19 con sus respectivos levares 28 - posee un comienzo anacrúsico y un final suspensivo, se encuentra conformado por dos movimientos diatónicos descendentes y se halla en el ámbito de la relativa mayor. Dicho antecedente es reiterado de manera variable por el ejecutante, probablemente con fines expresivos. Así, en la grabación, el mismo es repetido en sus dos apariciones en la primera décima, solo al final en la segunda -"La suerte cortó mi vuelo"-, únicamente al comienzo en la tercera -"Como fiera perseguida"-, y no es reiterado en la cuarta décima. Por otra parte, el consecuente (b) es tético, con final suspensivo, y posee un ritmo igualmente libre y lento. Al igual que "a", se compone por dos movimientos descendentes, en este caso el primero por saltos (mi-do-la-mi) y el segundo por grados conjuntos (re-do-si-la). La frase B, en cambio, posee un ritmo más definido y constante -con rallentando y accelerando mucho menos frecuentes-y es de tempo igualmente lento. Su antecedente y consecuente (c y d) son téticos y de final suspensivo, comparten un mismo patrón rítmico y un contorno melódico ondulante. El antecedente recorre sonidos del acorde de tónica, tiene una amplitud melódica de quinta y se organiza, fundamentalmente, a base de saltos de tercera -mayor y menor, ascendente y descendente-. El consecuente utiliza los sonidos del acorde de séptima de dominante y posee una amplitud melódica de séptima.

Por lo expresado hasta aquí, en lo que respecta a lo musical, este estilo se ajusta en términos generales a las definiciones del género mencionadas anteriormente: 1) está compuesto por dos "temas" (Aretz 1952: 144; Jacovella 1983: 8; Wilkes y Guerrero Cárpena 1946:

28 Alzares o anacrusas (Nota del editor). 
132-140); 2) cada uno de estos "temas" es subdivisible en dos "incisos" (Wilkes y Guerrero Cárpena 1946: 132-140); 3) se encuentra en modo menor pero explora su relativa mayor (Wilkes y Guerrero Cárpena 1946: 121-124); 4) el ritmo es predominantemente libre -el intérprete lo modifica a su voluntad con fines expresivos (Aretz 1952: 145)-; 5) se alternan pies binarios y ternarios (Aretz 1952: 145); 6) las cuatro estrofas son décimas espinelas; y 7 ) está acompañado por la guitarra (Aretz 1952: 145. Rossi 1926: 353). Esta descripción del estilo aporta, sin lugar a dudas, información significativa de sus rasgos musicales al tiempo que permite establecer diálogos con diferentes transcripciones. Sin embargo, la misma no agota en absoluto su caracterización debido a que excluye rasgos igualmente importantes para su definición y comprensión. El estudio de otras fuentes documentales -producidas en diferentes momentos históricos- permite, por un lado, advertir las limitaciones que acarrea la cristalización de un género a partir del análisis formal aislado y, por el otro, visibilizar los aspectos fundamentalmente cambiantes del género -e, incluso, pensarlos como rasgos propios del mismo y no como desplazamientos o variaciones de a una estructura ideal abstracta-.

En el libro Cosas de negros, Rossi presenta la transcripción de un estilo al que califica como anónimo y describe como un "exponente de la típica romanza rioplatense [...] popularizado por el drama 'Juan Moreira”" (Rossi 1926: 354). Es claro que esta versión -copiada a continuación ${ }^{29}$ - no se corresponde con la registrada en 1905. No obstante, el hecho de que este estilo sea identificado con aquel interpretado por Podestá y de que esté asociado a la misma décima del poema Lázaro permite considerarlo testimonio de su pervivencia en el imaginario colectivo rioplatense (ver Figura 2).

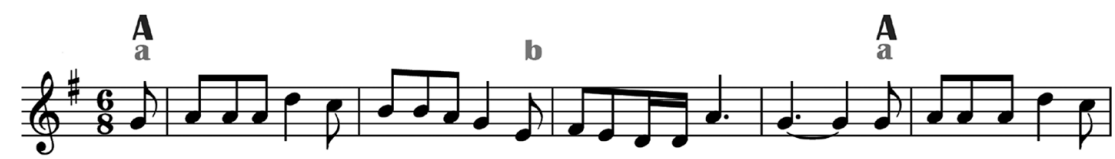

El hon-do pe-sar que sien-to y ya el al-ma me des-ga - rra So - 1lo-za en'es -ta gui-
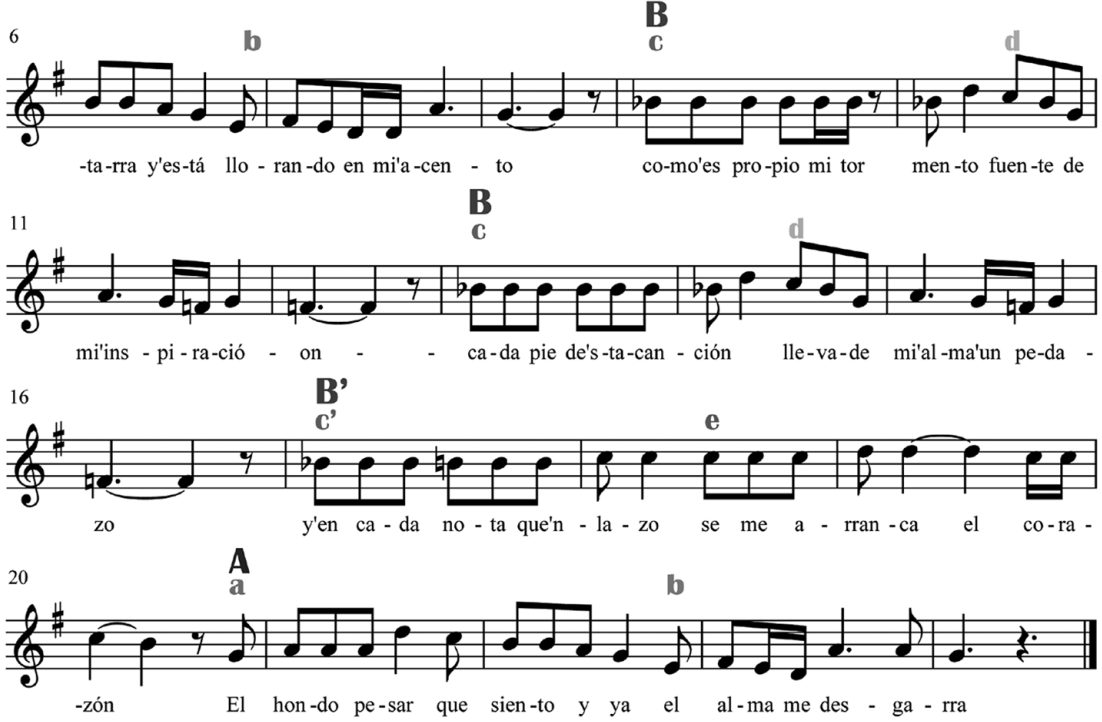

Figura 2: El hondo pesar, segunda versión.

${ }^{29} \mathrm{Si}$ bien en la transcripción publicada en su libro incorpora los acordes para interpretar esta pieza al piano, transcribo aquí únicamente la melodía -aunque me sirvo de esta información para desambiguar cuestiones armónicas-. 
A diferencia de lo que ocurre en el primer ejemplo, el modo de esta versión del estilo es mayor (sol mayor). En este caso, la pieza consta de dos frases bien diferenciadas, cada una de ellas subdivisible en dos, lo que da por resultado la siguiente forma: A A B B B' A ( $a b$ ab cd cd c'e ab). Si bien la frase A abarca dos versos octosilábicos completos, el antecedente y el consecuente no se ajustan, en este caso, a la métrica de la poesía. En términos formales, "a" posee un comienzo anacrúsico y un final suspensivo, se desplaza de V7 a I y está compuesto por el motivo rítmico corchea-tresillo-negra presentado dos veces. En la primera aparición, este motivo se articula sobre una nota repetida y un salto de cuarta ascendente, y en la segunda sobre un descenso por grado conjunto. El consecuente, anacrúsico y conclusivo, introduce el pie dactílico (corchea + dos semicorcheas), tiene un contorno melódico más ondulante y se mueve, también, de V7 a I. En la frase B, de carácter contrastante, se introduce una expansión tonal a si bemol -que puede ser considerada como un enlace por mediante-. El antecedente de esta frase (c), tético y suspensivo, está organizado a partir de dos tresillos sucesivos y una corchea en el tiempo fuerte del siguiente compás que repercuten sobre si bemol. Los sucede una negra que introduce el re en el tiempo débil. El consecuente (d), anacrúsico y conclusivo, posee en cambio un perfil melódico ondulante y una rítmica más variada. En su tercera aparición, la frase $\mathrm{B}^{\left({ }^{(}\right)}$es presentada con variaciones. El antecedente (c') se estructura sobre el mismo patrón rítmico que "c" pero varía armónicamente al regresar a Sol Mayor. El consecuente (e), realiza un movimiento por grado conjunto que bordea superior e inferiormente al do y traza una cadencia IV-V7-I que da lugar a la reexposición de A.

Otra de las fuentes en las cuales se alude a este estilo es el Cancionero popular cuyano recopilado por Draghi Lucero. En el mismo, la transcripción de una tonada titulada Que equivocación será se encuentra acompañada por la siguiente aclaración: "con esta música se popularizó 'El hondo pesar que siento' de Mitre (Draghi Lucero 1938: 595)”. Si bien este comentario puede parecer irrelevante, el mismo recoge y sintetiza una práctica frecuente en la época, a saber, el empleo de la música de una pieza -por lo general de gran popularidad-para interpretar otro/s texto/s. En los folletos y cancioneros extensamente difundidos durante el período ${ }^{30}$ se reproducen únicamente las poesías, por lo que aparecen con asiduidad aclaraciones tales como "[1] a música de este himno es la misma del Segundo Certamen Socialista” (ECR 1905: 4), "[p] ara cantar con la música del tango 'Cenizas'” (CP 1924: s/n), “'Canción del pito'. Música de 'Viva mi niña”" (ECR 1905: 20), “[p]ara cantar con la música del estilo criollo 'El Pangaré” (AM s/f [1911]: s/n), "El borracho. Para cantar con la tonada de 'La pastora”" (EFR 1918: 11), o “'Sombras!' Letra adaptable a la música del tango del mismo nombre” (CP 1924: s/n). La recurrencia de esta práctica devela la existencia de un imaginario musical colectivo -no necesariamente estático pero sí extendido-al que se apela con tales comentarios. Teniendo en consideración lo antedicho, la presencia de esa anotación junto con la transcripción de la tonada en el cancionero reunido por Draghi Lucero resulta significativa: no sería extraño que los intérpretes hubieran proporcionado esa información al recolector en su trabajo de campo. Si bien la atribución de autoría es equivocada -algo esperable para un saber que se reproduce oralmente y que no jerarquiza la figura del autor- y la música no se asemeja a la de ninguno de los dos

30 El corpus documental de mi tesis doctoral en curso está compuesto, entre otros documentos, por doscientos de este tipo. Gracias a su escrutinio he podido constatar que las tiradas de folletos y cancioneros oscilan, generalmente, entre dos mil y veinte mil ejemplares, que la mayoría fue editado al menos dos veces y que existen, incluso, los que fueron editados diez y hasta dieciséis veces en el lapso de nueve años. En el texto principal son indicados con letras que corresponden a las iniciales de sus títulos, las referencias completas están en la bibliografía. 
ejemplos presentados, la presencia de esta aclaración sugiere que: 1) el estilo permanecía vigente en el imaginario colectivo entrada la década de 1930 -incluso cuando no representara una expresión fija-; y 2) su popularidad había trascendido los límites de la provincia de Buenos Aires y se había extendido hacia la región de Cuyo. A continuación reproduzco la melodía sin letra, tal cual figura en el cancionero (ver Figura 3).

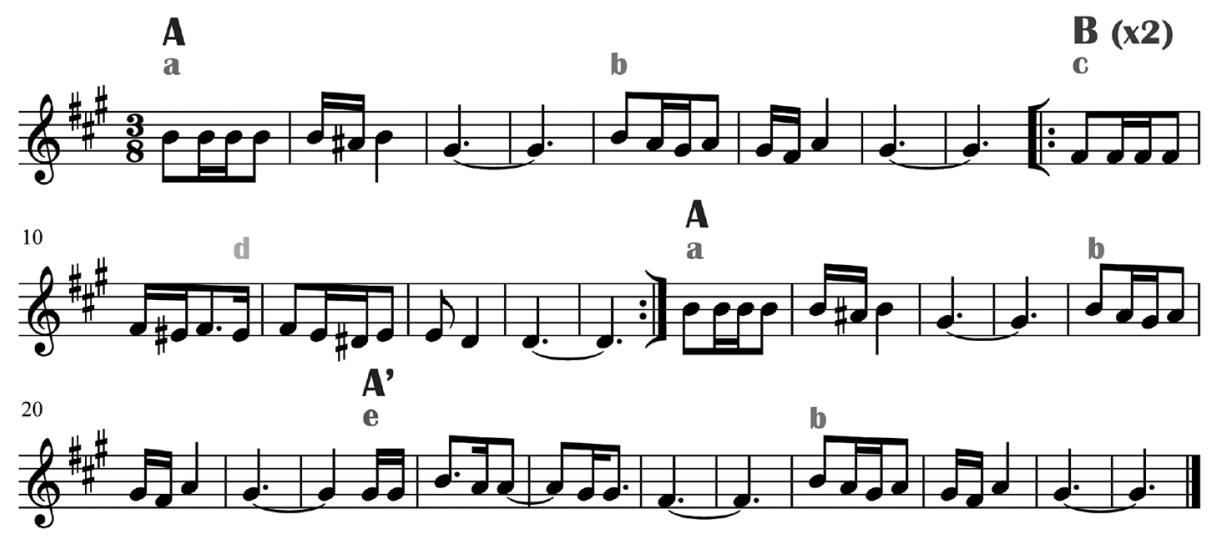

Figura 3: El hondo pesar, tercera versión.

$\mathrm{Al}$ igual que en los otros casos, esta versión del estilo cuenta con dos frases (A y B) que se componen, a su vez, por antecedente y consecuente ( $\mathrm{ab} c d \mathrm{~cd}$ ab eb). A diferencia de lo observado en los ejemplos anteriores, la frase "A" es la que tiene más apariciones en esta pieza (A B B A A'). Su antecedente (a) y su consecuente (b), de comienzo tético y final conclusivo, abarcan cuatro compases cada uno, poseen un contorno melódico ondulante y comparten el mismo patrón rítmico. La frase $\mathrm{B}$, en cambio, consta de un antecedente (c) de menor extensión que el consecuente (d), que se organiza a partir de figuras breves. Es importante destacar que, de acuerdo con lo indicado en la transcripción, la pieza debería estar en la mayor o fa sostenido menor. Sin embargo, su insistencia sobre si, la culminación de las frases en sol (\#) y su discurrir melódico sugieren el empleo de la escala bimodal.

El análisis formal de estas tres versiones permite develar, por un lado, que algunos de los rasgos del género establecidos como constantes en las definiciones mencionadas con anterioridad, son propensos a cambiar de un caso al otro sin que por esto ninguno deje de ser un estilo. De esta forma: a) el modo mayor no queda reservado a las modulaciones sino que puede constituirse en la modalidad central de la pieza; b) los dos temas no son siempre contrastantes y el segundo pocas veces resulta más "movido" o "vivo" que el primero; c) la alternancia de pies binarios y ternarios no aparece en todos los ejemplos -aunque esto puede tener que ver con decisiones del transcriptor-; y d) la estructura "exposición de A- exposición de B- recapitulación de A" se presenta siempre de una manera distinta (esto es, "A" puede tener más apariciones que "B" o viceversa, "A" puede exponerse dos veces al inicio de la pieza o dos veces en la recapitulación, etc.). Por otro lado, el análisis pone de manifiesto que estas tres versiones del estilo de Moreira no poseen características musicales que las emparenten -más allá de las vinculadas con su pertenencia a un mismo género-. Su forma, sus rasgos melódico-armónicos y su ritmo delinean, básicamente, tres expresiones musicales diferentes (ver Tabla 1). 
TABLA 1: CARACTERIZACIÓN FORMAL DE LAS TRES VERSIONES

\begin{tabular}{|c|c|c|c|}
\hline Versión / Rasgos & Forma & Tonalidad & Ritmo \\
\hline $\begin{array}{c}\text { Grabación } \\
\text { Lehmann-Nitsche } \\
(1905)\end{array}$ & $\begin{array}{c}\text { A B B B A } \\
\text { a(a)a cd cd cd a(a)a }\end{array}$ & La menor armónica & $6 / 8-2 / 4$ \\
\hline $\begin{array}{c}\text { Transcripción Rossi } \\
(1926)\end{array}$ & $\begin{array}{c}\text { A A B B B' A } \\
\text { ab ab cd cd c'e ab }\end{array}$ & $\begin{array}{c}\text { Sol mayor } \\
\text { (con expansión tonal } \\
\text { a si bemol) }\end{array}$ & $6 / 8$ \\
\hline $\begin{array}{c}\text { Transcripción } \\
\text { Draghi Lucero } \\
\text { (1938) }\end{array}$ & $\begin{array}{c}\text { A B B A A' } \\
\text { ab cd cd ab eb }\end{array}$ & $\begin{array}{c}\text { Mi menor } \\
\text { (empleo de escala } \\
\text { bimodal) }\end{array}$ & $3 / 8$ \\
\hline
\end{tabular}

Elaboración propia.

Sin embargo, estas diferencias no deben llevar a la conclusión de que se trata de tres piezas aisladas y desvinculadas entre sí. La recurrente identificación con el estilo interpretado en la obra Juan Moreira-sea por su alusión directa a la pantomima o a la poesía-denota una correspondencia entre los tres ejemplos que trasciende los aspectos musicales formales y deja entrever el carácter fundamentalmente dinámico de una pieza difundida oralmente. La reaparición de este estilo en los documentos desde finales del siglo XIX hasta entrada la década de 1930 da cuenta de su amplia difusión y popularidad, probablemente asociadas a su inclusión en la obra escénica ${ }^{31}$. En la portada de tres de las ediciones del folleto $D V$ (1897, s/f), por ejemplo, es transcrita la primera décima de esta pieza y lo mismo sucede en la primera página de ECP (1904). Asimismo, en el cuarto número de EFP (30 de octubre de 1911) se encuentran las cinco décimas tal como figuran en el libro de Ricardo Gutiérrez (1901 [1869]: 175-177) ${ }^{32}$. Esas mismas décimas conforman el manuscrito Folklore argentino $1905^{33}$, en el que Lehmann-Nitsche reúne, clasifica y transcribe más de noventa poesías para cantar populares durante el entresiglo.

31 La música empleada en las obras teatrales de la época -en especial en las de género chicoparece alcanzar una gran popularidad. De hecho, su presencia en las mismas es empleada como estrategia de difusión. Así, por ejemplo, en folletos o revistas se observan junto con los títulos de ciertas poesías aclaraciones como: “[t] ango que canta el Señor Rodolfo Migueres en la obra 'Trapos de seda'”, "[t]ango que canta la Señorita Ada Falcón" en la misma obra o "[e]strenado con gran éxito en la obra de A. Vaccarezza” (CP1924, III/35: s/n); "[t]ango sentimental. Cantado por el actor José Cicarelli en la obra 'Cuando un pobre se divierte"” (CP1921, I/7: 3); "[c] antado por la actriz Srta. Cafaro del Teatro Liceo" (BA 1926, IX/447); o "[e]stilo criollo de 'Piedra de escándalo”" (CT 1909: s/n; LA 1906: s/n).

32 Las décimas aparecen bajo el título "Trova".

33 Folios 169 a 171. Este manuscrito pertenece al denominado "Legado de Robert LehmannNitsche" que se encuentra en el archivo del Instituto Iberoamericano de Berlín. El mismo se compone de manuscritos de obras publicadas e inéditas, cartas, libretas, anotaciones sueltas, recortes de periódicos, bosquejos, documentos personales, fotos, álbumes de fotos, negativos fotográficos, álbumes de tarjetas postales y una extensa colección de publicaciones de literatura popular impresa. 
Si se tiene en cuenta que Juan Moreira estuvo en la cartelera teatral de diferentes ciudades argentinas y en Montevideo hasta fines del siglo XIX y que, según enuncia Podestá, en algunas temporadas fue puesta en escena más de cuarenta veces (Podestá 2003 [1930]: 61-62), no resulta extraño que el estilo haya permeado el imaginario colectivo local y que lo haya hecho como una expresión posible de ser interpretada con músicas diversas e, incluso, con combinaciones poéticas variables -sin por esto perder su identidad-.

\section{SIGNIFICACIÓN Y PERFORMANCE: UNA TRAMA COMPLEJA}

Como se ha dicho anteriormente, en los escritos musicológicos tempranos los autores recurren a rasgos estéticos -además de cuestiones formales- para definir el estilo. Estos rasgos son presentados como objetivos e, incluso, inmanentes al género y son enunciados desde el paradigma estético de la "cultura superior" o "letrada". Quedan, en todos los casos, excluidas de estas definiciones las conceptualizaciones o valoraciones emic. Esta exclusión origina contradicciones entre los discursos y la práctica musical concreta. Mediante la comparación de las características de la performance fijada por el fonógrafo de Lehmann-Nitsche en 1905 y de algunas de las apreciaciones más generalizadas en la literatura y la musicología respecto del estilo, es posible poner de relieve, precisamente, estos desajustes entre "teoría" y práctica.

En sintonía con las ideas de Philip Tagg (2004), puede afirmarse que los discursos musicológicos y literarios que refieren al estilo lo asocian mayormente al campo semántico de la "melancolía" y el "sentimentalismo". En estos discursos se destaca de manera recurrente la riqueza expresiva del género y se lo presenta como un medio eficaz para comunicar los sentimientos más íntimos del payador y para conmover a una audiencia. Sirvan de muestra los siguientes ejemplos: cuando Eduardo Gutiérrez narra en su novela Juan Moreira la escena en la que es interpretado este género, destaca que la guitarra irrumpe "en uno de esos estilos tristes y profundamente melancólicos que el gaucho toca con una extrema ternura" (Gutiérrez 1980 [1879-1880]:102), que "Moreira tocaba el estilo conmovido" (Gutiérrez 1980 [1879-1880]:102), que su interpretación "arrancó al auditorio las muestras del más patético entusiasmo" (Gutiérrez 1980 [1879-1880]:103) y que suscitó en varios de los presentes un llanto irrefrenable (Gutiérrez 1980 [1879-1880]:103). Asimismo, en Una amistad hasta la muerte, Gutiérrez afirma que "[los] estilos [...] son toda una pintura del espíritu, donde cada nota es un quejido y cada frase es un poema" (Gutiérrez 1952: 161); en los estilos el gaucho "[da] a la guitarra ese tinte de profunda melancolía y de suprema resignación" (Gutiérrez 1952: 161); y que en las fiestas es frecuente que los paisanos interpreten "sus quejumbrosos estilos" (Gutiérrez 1952: 117).

Vega, por su parte, asevera que en la versión circense de Juan Moreira, Podestá cantaba el estilo con gran dramatismo (Vega 2010b [1981]: 38), mientras que Lynch observa que en este género puede admirarse la intuición artística del gaucho y las cualidades de su voz, pues en él despliega al máximo su dulzura y musicalidad (Lynch 1883 [1953]: 33). Asimismo, Wilkes y Guerrero Cárpena aseguran que "[1]a expresión amable, delicada y tierna que trasuntaban [los estilos] se hizo cada vez más íntima y emotiva, por lo que se llegó a ver en ellos el género musical que mejor ponía en evidencia la gama expresiva del sentimiento rioplatense" (Wilkes y Guerrero Cárpena 1946: 122). Por último, Rossi observa que "[s] e llamó estilo a [...] la artística y sentimental canción popular, que el criollo conduce sin vacilaciones por el cordaje de su guitarra entre las más hermosas cadencias" (Rossi 1926: 353) y agrega que el mismo "se presta como ningún otro canto al lucimiento amplio de la letra, que se modula en un ritmo suave, dulce y sentimental” (Rossi 1926: 355).

Sin embargo, el registro fonográfico tomado en la ciudad de La Plata permite conocer aspectos de la performance que contradicen o, al menos, cuestionan algunas de estas 
valoraciones. La grabación comienza con un intercambio verbal entre diferentes actores ${ }^{34}$. Por un lado, se escucha la intervención de una posible audiencia, conformada por un hombre (al que llaman Varela ${ }^{35}$ ) y dos mujeres -nombradas como María y Clotilde-, quienes solicitan al intérprete que cante. Es posible escuchar frases como: "A ver, che, Rodríguez ${ }^{36}$, cantá algo", "A ver usted María pídale, hombre”, “Cante, Rodríguez, cante!”. Por otro lado, suena la voz del intérprete, quien en una primera instancia se rehúsa a cantar -con afirmaciones como "No hombre, ¡qué voy a cantar si no puedo!"- pero finalmente accede -"Bueno... haré lo que pueda, entonces"-. Al finalizar cada décima sobrevienen aplausos y, durante los interludios, reaparecen las voces de la audiencia solicitando al cantor que continúe. Este termina accediendo no sin antes negarse y justificar su presunta retirada con expresiones como "Che, Varela, a pesar de los aplausos no canto más porque lo estoy haciendo muy mal, es inútil que me pida", "una despedida para terminar y como final y no me pidan más”, “No me pidan más que ya estoy cansado, no me da la voz!”. Finalmente, luego de cantar la última décima el intérprete reclama: "Apenas terminé, ya ve hombre que no vale la pena", a lo que Varela le responde "Cantale otra, no ves cómo se han puesto las mozas". Esta dinámica se extiende hasta la culminación del registro que se corta en medio de los intercambios verbales.

Es cierto que esta grabación no puede ser considerada un ejemplo paradigmático de cómo era interpretado el estilo en la época. De hecho, al compararlo con otras del mismo género se perciben diferencias respecto al grado de interacción entre el músico y la audiencia. Sin embargo, el clima general es, en todos los casos, distendido y son frecuentes los aplausos y los comentarios jocosos entre décima y décima. Por ejemplo, en el cilindro $\mathrm{N}^{\circ} 24$ de la misma colección se encuentra el registro del estilo "La muerte de Diego Lamas" interpretado, según se enuncia en la grabación, por "el Gaucho Tormenta37". Al finalizar la segunda décima, cuyos últimos versos son "Fuego fatuo que se esfuma/ al contacto con la muerte", irrumpen los aplausos y un hombre grita desde la distancia "¡Ay, gaucho lindo!”. A continuación se escucha la voz de otro hombre, ronca y aparentemente más cercana a la bocina, cuyas palabras resultan inentendibles. Seguidamente, el cantor entona la última estrofa del estilo. Al finalizar vuelven a estallar los aplausos y los gritos. Reaparece la voz ronca que clama, en este caso, "ija ja ja! Es tremendo el paisano este" y de fondo se escucha al otro hombre que agrega "imuy bien gauchito! Gracias, eh”.

A su vez, en el cilindro $\mathrm{N}^{\circ} 85$ se halla el registro del estilo "La tapera" cantado por Juan M. Paul. Una vez finalizada la interpretación resuenan aplausos y gritos de fondo, en su mayoría ininteligibles debido al nivel de la señal sonora. Sin embargo, uno de ellos se escucha con claridad: "¡muy bien hermano, muy bien hermano... que cantás lindo, canejo!”. Finalmente, en el cilindro $\mathrm{N}^{\circ} 21$ que contiene la grabación de "El gaucho" -también interpretada por Garmendia- aparecen, de manera alternada, las voces de dos hombres ${ }^{38}$ quienes intervienen cuando el cantor termina de entonar cada una de las décimas. En esos momentos claman frases como "¡Otro trago de grapa!", "Ay negro si fueras blanco

34 Un análisis de los modos de enunciación en este registro y otros de la colección "Música criolla” en González 2017b.

35 Según las anotaciones de Lehmann-Nitsche, Juan Varela fue el músico que grabó la mayor cantidad de expresiones de la colección "Música criolla" (García y Chicote 2008: 64-65).

36 Como se mencionó anteriormente, el intérprete de esta pieza es Anastasio Rodríguez.

37 De acuerdo con lo registrado por Lehmann-Nitsche en el manuscrito Folklore argentino 1905 ese es el apodo de Miguel Garmendia.

38 Es importante destacar que una de las dos voces suena particularmente exigida, por lo que, podría tratarse del mismo hombre o, incluso, del propio cantor aparentando ser otro. 
qué lindos cantos tenés”, “Eche otra vuelta, pulpero!”, "Bravo, bravo, paisanito”, "Toque otro" y "iMuy bien ha cantao!".

El particular modo de interpretación del caso analizado -en conjunción con estos otros ejemplos- permite repensar los significados o las valoraciones asignadas al estilo desde la musicología y la literatura. El carácter patético e intimista adjudicado al género queda, en la versión grabada del "estilo de Moreira", eclipsado por la performance. Si bien la interpretación es sentida y expresiva no aparenta ser la manifestación de los sentimientos más hondos del payador y, sin duda, no promueve el recogimiento de la audiencia. El ambiente festivo en el que se desarrolla la interpretación ${ }^{39}$, la activa participación de quienes escuchan y la algarabía que resurge en los interludios permiten suponer que, entre sus cultores, el estilo no era un género necesariamente nostálgico y estremecedor, que demandara un clima específico o que estimulara un ánimo particular. Tampoco parece ser una expresión musical que requiriera un auditorio silencioso ni una ejecución sin interrupciones. Esto no quiere decir que la versión grabada invalide lo expresado por los discursos musicológicos y literarios. Sin embargo, las características de esta performance ponen de relieve la existencia de modos diferentes de valorar y de experimentar este género, modos que relativizan la perspectiva de la cultura letrada y abren paso a un conocimiento más profundo de estas expresiones musicales -compuestas y definidas por muchos más rasgos que los estrictamente formales-.

\section{REFLEXIONES FINALES}

Los estudios musicológicos tempranos referidos a las expresiones musicales populares argentinas tendieron a concebirlas como objetos sonoros aislados -de las prácticas performativas, de la acción transformadora de los sujetos, de las valoraciones y significaciones nativas- capaces de ser desglosados en y definidos a partir de sus "partes constituyentes" (Grebe Vicuña 1991: 10). Esta concepción de la música popular -extendida de manera más o menos velada en los discursos de los estudiosos locales- propició el desarrollo de estrategias analíticas fundamentalmente formalistas. Si bien en muchos escritos tales "objetos sonoros" fueron (re) introducidos en una narrativa historicista -que aludía al contexto histórico inmediato o a la función de dichas músicas- esto no impidió que los mismos fueran concebidos como esencialmente estáticos, analizados a partir de ciertos parámetros presuntamente inmanentes, y clasificados en géneros o especies musicales cristalizadas.

En términos generales, mediante el estudio del caso propuesto he buscado dar cuenta de: a) cuáles son los efectos que este modo de conceptualizar la música tiene en la definición del género y, fundamentalmente, en la elaboración de propuestas analíticas; b) qué límites presentan las perspectivas analíticas formalistas a la hora de dar cuenta de la multiplicidad de rasgos que componen las expresiones musicales; y c) cómo el desarrollo de análisis amplios y diacrónicos permite, por un lado, avizorar la densa trama de factores que constituyen estas músicas y, por el otro, poner de manifiesto el carácter dinámico de las mismas.

De manera específica, el estudio del "estilo de Moreira" ayudó a revelar la variabilidad de un género musical habitualmente entendido como inequívoco y estable, y la flexibilidad formal de una pieza sujeta a transformaciones profundas pero identificada de manera persistente como "sí misma" durante más de cuatro décadas. Esta identidad no tiene que ver con la constancia de sus características formales o sonoras a lo largo del tiempo sino con su

39 Es muy probable que la mayoría de las grabaciones que conforman esta colección se hayan realizado en ausencia del colector (respecto a esto, ver García 2006: 42-43). 
asociación recurrente en el imaginario colectivo a la popular obra escénica Juan Moreira. A su vez, la indagación y análisis de documentos heterogéneos propició la (re)inserción de esta música en su contexto específico, su (re)vinculación con los sujetos, y la visibilización de las tensiones entre las conceptualizaciones etic y emic.

No es el objetivo de este artículo agotar el debate respecto de las limitaciones con las que se encuentran las perspectivas analíticas formalistas, ni articular una propuesta de análisis claramente delimitada que permita desentrañar la compleja trama de factores que componen las expresiones musicales que se gestan en Buenos Aires durante el entresiglo. En todo caso, este artículo constituye un intento por abandonar el modo de análisis cristalizado en la bibliografía temprana por algunos "estudiosos canónicos" de la música popular argentina y señalar la importancia que tiene devolver la dimensión diacrónicoprocesual a estas músicas.

\section{BIBLIOGRAFÍA}

1) Libros, artículos y tesis

ARETZ, ISABEL

1952 El folklore musical argentino. Buenos Aires: Ricordi.

Carrizo, Juan Alfonso

1937 Cancionero popular del Tucumán. Buenos Aires: A. Baiocco. Vol. 2.

1945 Antecedentes hispano-medioevales de la poesía tradicional argentina. Buenos Aires: Publicaciones de Estudios Hispánicos.

Draghi Lucero, Juan

1938 Cancionero popular cuyano. Mendoza: Best Hermanos.

FRITH, SIMON

2014 [1998] Ritos de la interpretación. Sobre el valor de la música popular. Buenos Aires: Paidós.

García, Miguel

2006 "Una narrativa canónica de la música popular: A 100 años de las grabaciones de Robert Lehmann-Nitsche”, Revista Argentina de Musicología, 7, pp. 35-51.

2009 Robert Lehmann-Nitsche. Walzenaufnahmen aus Argentinien 1905-1909. Grabaciones en cilindros de Argentina 4/5. Historische Klangdokumente. Berlin: Berliner Phonogramm-Archiv, Staatliche Museen zu Berlin.

García, Miguel y Gloria Chicote

2008 Voces de tinta. Estudio preliminar y antología comentada de 'Folklore Argentino' (1905) de Robert Lehmann-Nitsche. Berlín: Ibero-Amerikanisches Institut. Buenos Aires: Editorial de la Universidad de la Plata y Centro de estudios de Teoría y Crítica Literaria.

García Velloso, EnriQue

1942 Memorias de un hombre de teatro. Buenos Aires: Kraft.

GonzÁlez, DANiela A.

2017a "La 'novela de la historia': formas hegemónicas de narrar la música popular argentina", Visões da América, Sonoridades da América. Atas do XII Congresso da IASPM-AL. Editado por Heloísa de A. Duarte Valente et al. (orgs.). Sao Paulo: Letra e Voz.

2017 b "El fonógrafo: entre el registro etnográfico y el anuncio de lo radiofónico", LIS. Letra. Imagen. Sonido. Ciudad mediatizada, IX/17, pp. 199-214.

González, Juan Pablo

2013 Pensar la música desde América Latina. Buenos Aires: Gourmet Musical. 
Goyena, Héctor y Norberto P. Cirio (eds.)

2015 Danzas y canciones argentinas. Versiones orquestales de registros de campo. Carlos Vega y Silvia Eisenstein (folleto). Buenos Aires: Instituto Nacional de Musicología.

Grebe Vicuña, María Ester

1991 "Aportes y limitaciones del análisis musical en la investigación musicológica y etnomusicológica”, Revista Musical Chilena, XLV/ 175 (enero-junio), pp. 10-18.

Guerrero, Juliana

2012 "El género musical en la música popular: algunos problemas para su caracterización", Revista Transcultural de Música, 16, pp. 2-16.

GutiérREz, EDUARDo

1952 [1886] Una amistad hasta la muerte. Buenos Aires: Lumen.

1980 [1879-1880] Juan Moreira. Buenos Aires: Centro Editor de América Latina.

Gutiérrez, Ricardo

1901 [1869] Lázaro. Buenos Aires: s/e.

Jacovella, Bruno

1983 Las canciones folklóricas de la Argentina. Antología (folleto introductorio). Buenos Aires: Secretaría de Estado de Cultura y Educación, Instituto Nacional de Musicología.

López CANo, RuBÉN

2013 "Lo original es la versión: covers, versiones y originales en la música popular urbana", ArtCultura, XIV/24 (enero-junio), pp. 81-98.

LYNCH, VENTURA

1953 [1883] Folklore bonaerense. Buenos Aires: Lajouane.

Marengo, María del Carmen

2004 "Las narraciones del entresiglo en Hispanoamérica: gozos y amenazas del saber (acerca de Lugones, Holmberg, Quiroga, Nervo, Clemente Palma)", Anuario brasileño de estudios hispánicos, 14, pp. 113-130.

MidDleton, RichaRD

1960 Studying Popular Music. Philadelphia: Open University Press.

NAGORE, María

2004 "El análisis musical, entre el formalismo y la hermenéutica", Músicas al Sur, 1. www.eumus. edu.uy/revista/nrol/nagore.html [acceso: 16 de noviembre de 2019]

Newland, Carlos

1999 "El sector agropecuario argentino en el período entresiglos (crecimiento económico e intensidad de factores). Una revisión historiográfica”, Revista de historia económica, XVII/1, pp. 225-234.

Podestá, José

2003 [1930] Medio siglo de farándula: memorias de José J. Podestá. Buenos Aires: Galerna.

Rodríguez, Alberto

1938 Cancionero popular cuyano. Buenos Aires: Numen.

Rossi, VICENTE

1926 Cosas de negros. Córdoba: Imprenta Argentina.

Salto, Graciela Nélida

2006 "La lengua literaria americana en la crítica de entresiglos", Orbis Tertius, 11/12, www.orbistertius.unlp.edu.ar/article/view/OTv11n12a20 [último acceso: 2 de mayo de 2019].

Seibel, BeAtriz

1993 Historia del circo. Buenos Aires: Ediciones del sol. 
Shirkin de Testado, Susana

2007 "El reinado teatral de María Guerrero en el contexto hispanoamericanista del entresiglo (1897-1928)". Tesis doctoral. Buenos Aires: Universidad de Buenos Aires.

TAGG, PHILIP

1979 Kojak, 50 Seconds of Television Music: Towards the Analysis of Affect in Popular Music. Göteborg: Göteborg University Musicology Department.

1982 "Analysing popular music: theory, method and practice", Popular Music, 2, pp. 37-67.

2004 Anti-depressants and musical anguish management. Presentación inaugural del V Congreso de la Rama Latinoamericana de la Asociación internacional para el estudio de la música popular. http://tagg.org/articles/iasprio0406.html [último acceso: 26 de junio de 2017].

Tagg, Philip y Bob Clarida

2003 "Method and Procedure", Ten Little Title Tunes. Towards a Musicology of the Mass Media. New York y Montreal: The Mass Media Musicologists' Press.

Vega, Carlos

2010a [1944] Panorama de la música popular argentina con un ensayo sobre la ciencia del folklore. Buenos Aires: Instituto Nacional de Musicología.

2010b [1981] Apuntes para la historia del movimiento tradicionalista argentino. Buenos Aires: Instituto Nacional de Musicología.

Wilkes, Josué T. e Ismael Guerrero Cárpena

1946 Formas musicales rioplatenses. Su origen hispánico. Buenos Aires: Publicaciones de Estudios Hispánicos.

ZanetTi, SusAna (COMP.)

1997 La novela latinoamericana de entresiglos (1880-1920). Buenos Aires: Facultad de Filosofía y Letras.

Ziegler, SusAnNe

2006 Die Wachszylinder des Berlin Phonogramm-Archivs (catálogo, CD-Rom con documentaciones de textos y muestras sonoras). Berlín: Ethnologisches Museum, Staatliche Museen zu Berlin.

2) Folletos y cancioneros

AM S/f [1911]. Aventuras de un ministro alemán en la Argentina. S/ed. Autor anónimo.

BA 1926. Bambalinas. Revista teatral, IX/447. Buenos Aires. Director: Enzo Aloisi. Autores varios.

CP 1921. Canciones populares. Tangos. Revista mensual, I/ 7. Buenos Aires. Editor: Raúl Gómez. Autores varios.

1924. Canciones populares. Tangos. Revista mensual, III/ 35. Buenos Aires. Editor: Raúl Gómez. Autores varios.

CT 1909. Cantos tristes por Julián Lecea y otras canciones porvarios autores. Buenos Aires. Casa editora de Andrés Pérez.

DV 1897. Décimas variadas para cantar con guitarra. $16^{\mathrm{a}}$ edición. Buenos Aires. Editor: Joaquín A. Llambias. Autor: Sebastián C. Berón.

s/f. Décimas variadas para cantar con guitarra. Buenos Aires: Biblioteca Gauchesca. Autor: Sebastián C. Berón.

s/f. Décimas variadas para cantar con guitarra. Buenos Aires. Autor: Sebastián C. Berón.

ECP 1904. El cancionero popular. Colección de décimas amorosas para cantar con guitarra. Tercera serie. Valparaíso: Imprenta de la Librería de El Mercurio. Autores varios. 
ECR 1905. El cancionero revolucionario ilustrado. Colección de himnos y canciones libertarias en español é italiano. Himnos revolucionarios. Buenos Aires. Editor: Bautista Fueyo. Autores varios.

EFP 1911. El fogón pampeano. Periódico criollo ilustrado, 1/4. Rosario. Director: Francisco J. Neira. Autores varios.

EFR 1918. El fajador rosarino. Décimas arrabaleras. Buenos Aires y Rosario. Editores: Vicente Matera y Longo y Argento. Autor: Antonio F. Rodríguez.

LA 1906. Los amores de un tarugo con la parda Filumena. Buenos Aires. Casa editora de Andrés Pérez. Autor: Giuseppe di Papanova (pseud.). 